\title{
LA NOVA CANCÓ CATALANA: GÉNESIS, DESARROLLO Y TRASCENDENCIA DE UN FENÓMENO CULTURAL EN EL SEGUNDO FRANQUISMO
}

Carlos Aragüez Rubio

A mediados de los años cincuenta, la trayectoria de la España franquista emprende un leve viraje abandonando las posturas posbélicas que habían marcado los primeros años de dictadura tras el final de la Guerra Civil. Esta nueva dirección se ejemplifica en el cambio gubernamental que sustituye la mayoría política de Falange por un nuevo grupo mayoritario al frente de la dirección del Estado, el Opus Dei. En el mismo sentido, hechos como el abandono de la política autárquica y reformas como la puesta en marcha de los Planes de Estabilización y Desarrollo, van a tener su repercusión en una sociedad española que comenzará a experimentar algunos cambios.

Es evidente que la sociedad de los sesenta, ya no es la misma que la que vivó el nacimiento y consolidación del Régimen en la década de los cuarenta. No sólo los cambios políticos, sino también el cambio generacional que conlleva la aparición de una juventud más activa y menos atemorizada, hacen de los sesenta una época de especial trascendencia cultural en la historia española. Y si a esto añadimos la mayor permeabilidad a los fenómenos culturales foráneos que posibilita la nueva política de "aperturismo", nos encontramos ante un período crucial que marca el comienzo de un renacer cultural cuya evolución continuará hasta el final del Régimen y la Transición a la democracia.

En este contexto es en el que hay que ubicar el nacimiento y desarrollo de un fenómeno cultural de gran importancia, no sólo en el segundo franquismo, sino también en tiempos de Transición, pues su simbología y relevancia permanecerá muy vigente en el proceso de democratización del país. Nos referimos a lo que, en sus comienzos, vino a denominarse "Nova Cançó Catalana» pero que, con el paso del tiempo, pese a conservar el nombre genérico, traspasó las barreras regionales para convertirse en un fenómeno cultural de impacto nacional. La descripción de este proceso de crecimiento, junto con el análisis de su 
importancia social e incluso política en la España del segundo franquismo, es lo que trataremos de desarrollar en las próximas líneas.

\section{INTRODUCCIÓN: ¿QUÉ ES LA NOVA CANÇÓ?}

Primavera de 1965. En la joven revista musical Fonorama, con sede en Madrid, el periodista Fernando Morer Alcántara se pregunta "¿Qué es la Nova Cançó Catalana?» ${ }^{1}$. En ese momento el fenómeno está comenzando a trascender a nivel nacional y se trata de explicar al público español en qué consiste el movimiento. Lo cierto es que el artículo no supone una respuesta exacta a la cuestión, pero sí ofrece algunas pistas. Fernando Morer habla de nuevos cantantes que hacen música en lengua catalana bajo un único sello discográfico, Edigsa. Y establece una primera distinción: hay cantantes que alternan grabaciones en castellano con discos en catalán, pero hay otros que sólo cantan en catalán. En ese momento aparece el nombre de Raimon, la primera gran estrella del movimiento. Junto a él se citan otros como los de Delfí Abella, José María Espinás, Remei Margarit, Guillermina Motta o Enric Barbat.

En un primer momento, el término «Nova Cançó Catalana» comienza a aplicarse a todas aquellas grabaciones que empiezan a aparecer en catalán desde $1958^{2}$. Pero a medida que el tiempo pasa, la definición va a ir ajustándose, ya no sólo a cantar en catalán, sino a hacerlo de una determinada forma y expresando determinadas inquietudes. Pero, lo más importante, el término "Nova Cançó", desde comienzos de los sesenta, va a ir unido a una defensa manifiesta de la lengua y la cultura catalana, dormida y silenciada desde tiempos de la República. Por ello, no era baladí la distinción que se hacía en el artículo de Fonorama. Era importante diferenciar a aquellos que cantaban también en castellano, de los que sólo lo hacían en catalán. Precisamente de ahí, como veremos más adelante, vendrían las primeras crisis del movimiento y sus cambios de rumbo. Sería Joan Manuel Serrat el que encendería la mecha, siendo uno de los símbolos de la Nova Cançó y grabando discos también en castellano, con un grandísimo éxito de ventas.

En realidad, a partir de 1963, cuando se habla de Nova Cançó Catalana inmediatamente se va a tender a pensar en un reducido grupo de intérpretes, en concreto, aquellos agrupados en el colectivo Els Setze Jutges, el propio Raimon, que aunque no pertenece directamente al grupo comparte con ellos galas y recitales, y otras pequeñas agrupaciones como Els quatre gats y, algo posteriormente, el denominado Grup de Folk, de donde saldría, por ejemplo, una de las

1. MORER AlCÁNTARA, Fernando, "¿Qué es la Nova Cançó Catalana?», Fonorama, n. 14 (1965), pp. 10-11.

2. Es en 1958 cuando se editan los primeros discos en catalán. El sello La Voz su Amo publica el 45 r.p.m. titulado Hermanas Serrano cantan en catalăn los éxitos internacionales y Regal publica algo similar en José Guardiola canta en catalán los éxitos internacionales. 
voces femeninas más carismáticas del movimiento, la mallorquina Maria del Mar Bonet ${ }^{3}$.

La Nova Cançó no es, pues, un movimiento simple y homogéneo, sino que se trata de una serie de aportaciones músico-literarias de carácter heterogéneo que fueron agrupadas bajo un solo nombre con el que compartían una lengua y una cultura que había de ser reivindicada.

Pero para entender mejor esa heterogeneidad y sus características, se requiere un análisis profundo de su nacimiento y posterior evolución, que realizaremos a continuación.

\section{NACIMIENTO Y FORMACIÓN}

Las raíces del nacimiento de la Nova Cançó hay que buscarlas sin ninguna duda en los años cincuenta. A comienzos de la década, en el seno de la pequeña burguesía barcelonesa, existe un reducido grupo de jóvenes que comienza a interesarse por el estado de la cultura en lengua catalana y a profundizar en sus raices y manifestaciones. Dos de ellos, Miquel Porter y Eulalia Amorós, empiezan a organizar reuniones en los claustros de la Facultad de Filosofía y Letras de Barcelona para debatir sobre estos temas. A partir de 1953, estas reuniones se establecen los jueves por la noche y en ellas, no sólo se empiezan a cantar y escribir letras en catalán, sino que también se realizan traducciones y adaptaciones de poemas y canciones internacionales.

Poco a poco se van a ir incorporando a las actividades algunos de los nombres claves en la gestación del movimiento. Ya en 1958, se celebran periódicamente pequeños conciertos en casa de Josep Porter en los que participan Lluís Serrahima, Miquel Porter, Remei Margarit y Josep Maria Espinás, entre otros. Ellos serán los que, años después, comiencen a actuar por Cataluña con el nombre de Els Setze Jutges.

Es precisamente ese año cuando se editan los primeros discos con canciones en catalán que, si bien son meras traducciones de éxitos internacionales, suponen un punto de partida importante para el nacimiento de una canción catalana.

Pero probablemente el año clave es 1959. Como más tarde escribirían Joaquim Molas y Josep Maria Castellet en el marco de la historia literaria, se trata de un momento crucial en el que "la vida de catacumba se relaja», los escritores salen de sus estudios entrando en contacto con otros y, sobre todo, «el panorama se airea al entrar en juego unas nuevas generaciones que pugnan por fijar unos esquemas de conducta ${ }^{4}$. Es precisamente uno de esos jóvenes, Lluís Serrahima, quien en enero de ese año publica en la catalana revista Germinabit

3. Es en "Cataluña Exprés" cuando el 23 de enero de 1962 se comienza a hablar de "Nova Cançó" refiriéndose únicamente a los primeros componentes del grupo que poco después se denominaría Els Setze Jutges y a Raimon. El grupo Els quatre gats y el Grup de Folk, todavía no habían nacido.

4. Castellet, J. M. y Mol.AS, J., Poesia catalana del segle XX, Barcelona, Edicions 62, 1963, pp. 178-179. 
un artículo que, para la mayoría de estudiosos sobre el tema, constituye el pistoletazo de salida de la Nova Cançó, aunque este término no se utiliza hasta 1962. En él, Serrahima habla de potenciar un fenómeno cultural nuevo en el ámbito catalán, y de hacerlo a través de la canción, uniendo música y literatura en un mensaje actual que reflejara el momento en que se vivia ${ }^{5}$. El título del artículo no podía ser más aclarador: "Necesitamos canciones de ahora». Esta afirmación se convertiría, desde ese momento, en la bandera de un fenómeno que comenzaba a dar sus primeros pasos.

Se estaban poniendo las bases del movimiento y en algunos círculos se hablaba seriamente de las posibilidades de una canción catalana de rigor y entidad. Incluso, en la primavera de 1961, la organización de algunos festivales de la canción con sede en Cataluña como el recién nacido Festival de la Canción Mediterránea o el Aplec a Paret Delgada, empiezan a plantearse la posibilidad de incluir algunas de las nuevas canciones en catalán en sus próximas celebraciones. Además, en el mes de mayo, Miquel Porter, Lluís Serrahima y Remei Margarit publican sus primeras canciones en un cuadernillo que contiene seis temas en catalán ${ }^{6}$. Un hecho que comienza a dar relevancia al movimiento y hace que se interesen en él otros intérpretes como Font Sellabona o el propio Josep Guardiola, uno de los pioneros en la grabación de temas cantados en catalán. El 30 de septiembre de 1961 tiene lugar en el Centre Comarcal Lleidetà la primera audición pública únicamente dedicada a canciones en catalán. Allí actúan el Conjunt Diavolos, Josep Guardiola (estos cantando traducciones de temas conocidos) y Miquel Porter con sus propias canciones. Además, se reparte al público letras de Espinás, Margarit, Serahima y el propio Porter.

Tras el éxito de este recital, en el mes de noviembre se empieza a hablar en serio de la posibilidad de iniciar la publicación de discos de canción catalana. En diciembre el proyecto ve la luz con la publicación de un primer disco, titulado "Bon Nadal» donde la Coral Sant Jordi interpreta un poema de Josep Maria de Sagarra y otras canciones tradicionales navideñas en catalán. La publicación aparecerá con el sello donostiarra Ediphone y bajo la denominación "Serie Especial Edigsa». Podemos decir que es el nacimiento de la Editora General Sociedad Anónima (EDIGSA) que, desde ese momento, representará discográficamente las andanzas de la Nova Cançó.

Pero 1961 no acabaría ahí, sino que el 19 de diciembre, en el club CICF 7 de Barcelona, tiene lugar la primera audición pública del grupo que poco más tarde pasaría a denominarse Els Setze Jutges. Allí actuarán Miquel Porter, Josep Maria Espinás y Lluís Serrahima, causando baja Remei Margarit por enfermedad y cuyas canciones se reprodujeron en cinta magnetofónica. La reacción no se hizo

5. SERAHIMA, Lluís, "Ens calen cançons d'ara», Germinabit, n. 58 (1959), Barcelona, p. 15.

6. Los seis temas son: "Les floristes de la Rambla», "La cançó de la taverna", "Mester d'amor-Divisa", "Noia que camines", "Jo i el meu gat" y "Anant pel món". Ver PORTER-MOIX, Josep, "Breve cronología de la canción catalanan, en VÁZOUEZ MONTALBÁN, Manuel, Antología de la Nova Cançó, Barcelona, Ediciones de Cultura Popular, 1968, pp. 275-289.

7. Centro de Influencia Católica Femenina. 
esperar y, poco después, la prensa catalana comenzaba a hablar del acontecimiento, del nacimiento de nuevos intérpretes con canciones catalanas y de un importante avance cultural. En concreto, Arturo Llopis, en el semanario Destino, no duda en calificar la velada del 19 como "auténticamente memorable» ${ }^{8}$. Los meses siguientes empieza a hablarse ya claramente de "Nova Cançó Catalana» en publicaciones como Cataluña Exprés ${ }^{9}$ o el Diario de Barcelona.

1962 es el año del despegue de la Nova Cançó. Las actuaciones empiezan a sucederse cada vez con mayor frecuencia desde primeros de año por toda Cataluña. En una de ellas, en febrero, Espinás y Porter conocen a Delfí Abella que se une al grupo. Y en marzo entablan contacto con Francesc Pi de la Serra quien, a la postre, sería uno de los miembros más importantes de El Setze Jutges. Pero no es hasta el 29 de abril de ese año hasta que los «16 Jueces" no actúan por primera vez con el nombre que los haría famosos como grupo de referencia cultural catalana. La actuación tendría lugar en el denominado "Festival de la Cançó Catalana Moderna» organizado por la Peña Barcelonista de Premià de Mar, en una jornada matinal que marcaría los designios de un movimiento cuya formación cada vez estaba más consolidada.

El 21 de octubre se iba a producir otro acontecimiento capital en la formación del fenómeno. Els Setze Jutges actúan en Castellón de la Plana donde coinciden con un joven intérprete valenciano que también había comenzado una humilde labor de cantautor en lengua catalana. Su nombre es Ramón Pelegero Sanchis, pero ante el público se presenta como Raimon. Ambos se escuchan, se admiran y traban una gran amistad. A partir de ese momento, Raimon comenzaría a compartir cartel asiduamente con Els Setze Jutges, dando una mayor cohesión al movimiento.

La Nova Cançó, con todas las características y especialidades que analizaremos, estaba constituida. El nuevo fenómeno cultural había empezado a volar, pero el gran impacto mediático y nacional llegaría en septiembre de 1963. Los días 20, 21 y 22 se celebraba en Barcelona el V Festival de la Cançó Mediterránea, de carácter internacional y cada vez de mayor popularidad entre público y crítica. Por primera vez en la historia, una canción en catalán vence en un certamen de índole nacional o internacional. El tema, escrito por Josep Maria Andreu y con música de Lleó Borrell, se titulaba S'en va anar y fue interpretado por Salomé y Raimon. El éxito fue mayúsculo y, también por primera vez, la prensa nacional se hacía eco de la canción catalana, catapultando a Raimon al estrellato de la música nacional. Jesús García de Dueñas escribía así sobre él en las páginas de la revista Triunfo: «Éste es Raimon. No se puede decir que sea la revelación del festival. Es eso y mucho más. Raimon marca una actitud consciente en este panorama un tanto anárquico de la música ligera española. Posiblemente sea la primera vez que alguien se haya propuesto una renovación

8. Llopis, Arturo, "Con José María Espinás, ganador del Premio "Sant Jordis», Destino, n. 1271 (1961), Barcelona, p. 113.

9. Es en esta publicación en la que se habla por primera vez de «nova cançó catalana». Ver "Entrevista a Miquel Porter», Cataluña Exprés, n. ${ }^{\circ} 8$ (1961), Barcelona, p. 7. 
tan lúcida de la canción española. La voz de Raimon ha surgido en medio del desierto. Hay que escucharla. $Y$ hay que seguirla» ${ }^{10}$.

\section{TENDENCIAS Y EVOLUCIÓN DE UN MOVIMIENTO HETEROGÉNEO}

Hemos enunciado el proceso cronológico de formación de la Nova Cançó Catalana, el cual no frenaría en 1963 sino que iría creciendo cuantitativa y cualitativamente en los años posteriores. Pero éste no se entiende sin un análisis de las motivaciones y peculiaridades que marcan el nacimiento del fenómeno. El interés por rescatar la cultura catalana del anonimato es el motor básico, pero de éste se derivan otras importantes características como el uso público y artístico de la lengua catalana y la búsqueda de un espacio propio para lo catalán en el panorama cultural español. Estas claves explican perfectamente los rasgos especiales que la Nova Cançó va a tener en sus primeros momentos. El ejemplo más evidente es que cuando Porter, Serrahima, Espinás o Margarit comienzan a elaborar un repertorio propio, éste combina canciones en catalán que describen con gran simplicidad hechos cotidianos de la Barcelona de fines de los cincuenta, con la sonorización de textos literarios catalanes. Como ha contado el especialista Llorenç Soldevila, si las nuevas generaciones de poetas que emergen en este momento siguen el maestrazgo de Pere Quart y Salvador Espriu, lo mismo harán los primeros integrantes del movimiento, poniendo música a algunos de sus textos más conocidos ${ }^{11}$. Junto a ellos, también se acude a otros literatos que también se convertirán en referencia como Joan Salvat-Papasseit que aportará su vanguardismo a los temas de la Nova Cançó. En cuanto a la búsqueda de raíces de la cultura catalana, quizás uno de los que más representó esta actitud fue Raimon, que no sólo acudió en su música a textos de escritores contemporáneos, sino que también alargó su búsqueda en el tiempo rescatando escritos de poetas clásicos como Ausiàs March.

Pero las características de la Nova Cançó quedan algo huérfanas solamente citando las raíces literarias, pues también serán de vital importancia las influencias estéticas en las que se mira el movimiento. Éstas, al menos en una primera época, parecen venir inequívocamente de la música francófona de autor que se está generando desde hace algún tiempo, por encima de la influencia italiana que parecía dominar la canción ligera española del momento. Dos parecen, claramente, las referencias de mayor trascendencia: la estética musical del belga Jacques Brel y la actitud vital y forma de contar de Georges Brassens quien, como dice Josep Porter-Moix, llegó a implicarse directamente en los proyectos de grabación en lengua catalana cediendo textos a los nuevos intérpretes ${ }^{12}$. Posteriormente, ciertos representantes de la Nova Cançó se dejarán influir tam-

10. GARCÍA DE DUEÑas, Jesús, "En busca de la canción perdida. V Festival de la canción Mediterránea", Triunfo, n. 69 (1963), Madrid, pp. 26-33.

11. SOlDEVILA I BALART, Llorenç, La Nova Cançó (1958-1987). Balaņ̧ d'una acció cultural, Argentona, L'Aixernador Edicions, 1993, p. 31.

12. PORTER-MOIX, Josep, op, cit., 1968, p. 276. 
bién por el Folk norteamericano que en los sesenta está en plena ebullición. Por ejemplo, en algunos foros musicales del momento se llega a bautizar a Raimon como «El Bob Dylan español»"

Es evidente que lo que enunciamos son las influencias comunes que marcan la primera época del movimiento, pero, y de ahí la heterogeneidad del fenómeno, cada intérprete o grupo asimilará éstas de forma distinta según su personalidad. A partir de un determinado momento en el que la Nova Cançó toma vuelo y entidad de fenómeno cultural a media escala, se van a percibir con claridad las diferentes tendencias por las que cada representante va a ir derivando. Por ejemplo, la acidez textual y el vanguardismo estético de personajes como Enric Barbat o Pau Riba, se irá distanciando de la expresividad y sobriedad poética de otros intérpretes como Ovidi Montllor o el propio Raimon. Estas distintas tendencias de las que hablamos van a ir planteándose a lo largo de los años, pues la trayectoria de la Nova Cançó, según la mayoría de estudios realizados, tiene un amplio recorrido cronológico que se ha venido a datar desde 1958 a 1987 , aunque en estas líneas sólo nos fijemos en, aproximadamente, los primeros quince años de vida del movimiento.

Evidentemente, tan larga trayectoria se puede dividir en distintos bloques cronológicos según diversos condicionantes de los que nos haremos eco. Una razonable división cronológica parece la que plantea Llorenç Soldevila en su tesis doctoral. En ella se secciona cronológicamente a la Nova Cançó en tres períodos diferenciados: El primero transcurre de 1958, fecha simbólica de nacimiento, a 1968, momento en el que el movimiento parece atravesar una cierta crisis de identidad que supone un punto de inflexión en su trayectoria social y cultural. El segundo se establece desde 1969 a 1975, años en los que la «cançó» se vuelve más política y que finalizan con la muerte del dictador. Y el tercero, de 1976 a 1987, comienza con el período de transición democrática. y concluye con la consolidación de ésta y la pérdida de fuerza e interés por la "cançó catalana»".

Precisamente ese primer bloque cronológico, además de marcar el despegue cultural del movimiento, va a ser en el que se creen las distintas tendencias en el seno de la Nova Cançó. Unas tendencias que son inevitables si pensamos en que el fenómeno, que comienza como algo absolutamente minoritario, va a ir cogiendo relevancia y tamaño añadiendo a él representantes de toda la franja geográfica catalano-parlante. El ejemplo de Els Setze Jutges, uno de los símbolos del movimiento, es revelador. El grupo, que comienza con cuatro miembros, irá a lo largo de los años añadiendo nuevos representantes a su seno hasta llegar a dieciséis en marzo de 1967, con la entrada de los dos últimos: Lluís Llach y Rafael Subirachs. Resulta lógico pensar que, entre dieciséis personas, cada uno vaya forjando su propio estilo $y$, aunque siempre dentro de unas pautas gene-

13. Véase como ejemplo una nota informativa de RADIAL PrESS, "Raimon, el Bob Dylan español, siempre es notician, Fans, n. 60 (1966), Madrid, p. 19.

14. SOLDEVILA I BALART, Llorenç, La Nova Cançó, 1958-1987: 30 anys d'un fenomen cultural modern, Barcelona, Universidad Autónoma de Barcelona, 1992, pp. 2-4. 
rales, su propio pensamiento y posición ante la realidad social y cultural del momento. Decir esto puede parecer obvio, pero resulta preciso para entender la evolución de la Nova Cançó, pues las diferentes posturas ideológicas serán las que quiebren la cohesión de los primeros tiempos.

Si en un principio la Nova Cançó se articula como reivindicación de las posibilidades de la cultura catalana, cuando el movimiento explota en popularidad y se convierte en un género musical a nivel nacional, las exigencias del fenómeno van a ser cada vez mayores. Ya no va a bastar con escribir y cantar públicamente en catalán, sino que a través de estas manifestaciones se tiene que mostrar una postura de defensa cultural firme y decidida. Pero, y ahí comienzan las diferencias, esta postura no será igualmente entendida por todos. Surge entonces en el seno de la Nova Cançó una división entre "puros" e "impuros", relacionada con la defensa menos o más fuerte de lo catalán en el sentido de las concesiones a la cultura en castellano. Quizás el ejemplo a través del cual mejor se ejemplifica esta diferenciación es Joan Manuel Serrat. Él hace su irrupción en el panorama musical catalán en 1965 y al año siguiente ya es reconocido como uno de los artistas de moda en toda la geografía española ${ }^{15}$. Pero pronto acepta la oferta de grabar discos también en castellano, lo que definitivamente le catapulta al estrellato a nivel nacional. Esto para algunos significaba romper con el "purismo" del movimiento y hacer concesiones fuera de la defensa cultural catalana. Uno de los más ávidos defensores de esta postura fue Raimon quien se consideraba "cantante puro de la Nova Cançó» y veía el bilingüismo como un peaje que había que pagar para "cantar en Televisión Española». Tenía muy clara su postura: «Si cantas en dieciocho idiomas que no son el tuyo, puede que seas «universal», pero acabas no cantando para nadie. Insisto. ¿Por qué no cantamos en Televisión? Yo actué cinco minutos en 1964 y supongo que por despiste de alguien. Después se han tomado la molestia de enterarse sobre lo que canto y no me han vuelto a programar. Repito ¿Por qué?» ${ }^{16}$.

En ese momento las figuras más relevantes del movimiento van a comenzar a tomar posturas. Desde los que deciden mantenerse al margen y seguir con su lenguaje simbólico y sus experimentaciones vanguardistas como Pau Riba, a los que apoyan a Raimon y su postura firme frente a aquellos que no creen la necesidad de tanta rigidez y aceptan como buenas las posturas de bilingüismo, siempre que se siga cantando, a la par, en la lengua propia. De entre los "puristas», empiezan a sobresalir tres nombres junto al del propio Raimon: Francesc Pi de la Serra, Ovidi Montllor y un joven Lluís Llach, cuya entrada en la Nova Cançó se produce ya en 1967. Sobre ellos, en el interesantísimo trabajo sobre

15. La revista Fans, de ámbito nacional, le dedica entonces un amplio reportaje en el que se da fe del gran éxito que ha cosechado en poco tiempo gracias a temas como "Cançó de matinada". Ver CRESPO, Ramón, "Juan Manuel Serrat. Escribe, compone y canta sus canciones", Fans, n. 73 (1966), Madrid, pp. 15-18.

16. Todas estas afirmaciones las realizó Raimon en una entrevista concedida a Manuel Vázquez Montalbán en 1968 y publicada en el libro Vázouez MONTALbÁn, Manuel, Antología de la Nova Cançó Catalana, Barcelona, Ediciones de Cultura Popular, 1968, pp. 45-49. 
La Nova Cançó que Vázquez Montalbán publica en 1968, otro de los miembros del movimiento, Enric Barbat, dice que "son exclusivos y excluyentes. Son el "Clan Sinatra» de la Nova Cançó»"17. Para Guillermina Motta, sin embargo, la cosa va más allá. No cita nombres pero es muy explícita acerca de las causas de la división: "La "cançó" comenzó a escindirse el día que un señor, o quizás dos, empezaron a sentir envidia al ver cuanto dinero ganaba Serrat» ${ }^{18}$.

Cuestión monetaria o no, lo cierto es que la división estaba a la orden del día. Y no sólo en cuanto a la actitud personal de cada intérprete, sino también a nivel discográfico y empresarial. En este caso la escisión se concretó con la separación de Ermengol Passola, fundador de la discográfica que puso en marcha la Nova Cançó (EDIGSA), que abandonó el proyecto "por criterios de elección y selección de cantantes ${ }^{~}{ }^{19}$, creando un nuevo sello discográfico de nombre Concéntric y con un dragón como emblema. Éste dragón también se convertiría en el símbolo de un local de Barcelona que, desde ese momento, pasaba a ser el lugar de referencia de la Nova Cançó: La Cova del Drac.

Passola no fue el único que abandonó Edigsa, pues Raimon y Pi de la Serra también se sumaron a la escisión por cuestiones económicas y por considerar que la discográfica ya no mantenía la unidad de criterios con la que había nacido.

El movimiento atravesaba por lo que Jordi García-Soler ha venido a denominar "crisis de crecimiento" 20 . El fenómeno había adquirido tal magnitud que era inevitable una ruptura con la cohesión primera. Pero esto, lejos de debilitar a la Nova Cançó, la convirtió en un género más rico y vivo cuyos representantes cada vez estaban más en los gustos de muchos jóvenes, no sólo catalanes, sino de todo el territorio español. Como escribiría Luis Carandell en el verano de 1969, a pesar de la supuesta «crisis», todas las noches la Cova del Drac volvía a convertirse en escenario de canciones, encuentros y reuniones ${ }^{21}$ de un movimiento cuya importancia, no sólo seguía muy vigente, sino que todavía iba a crecer más.

\section{CANÇÓ Y POLÍTICA: UNA RELACIÓN INEVITABLE}

Si 1963 y el abrumador triunfo de S'en va anar en el Festival de la Canción Mediterránea supone el despegue definitivo del movimiento, 1968 supone otro momento crucial para la Nova Cançó, que va a marcar el nacimiento de una segunda época de su trayectoria, no sólo por la crisis de la que hemos hablado ni por la heterogeneidad que ya manifiesta el fenómeno, sino por la importancia política que va a comenzar a adquirir, a pesar de que los cantantes del movimiento nieguen en repetidas entrevistas que hagan canción política. Sin duda el

17. Ver entrevista a Enric Barbat en Vázouez MONTALBÁN, Manuel, op. cit., 1968, pp. 31-35.

18. Ver entrevista a Guillermina Motta en Ibidem, pp. 41-45.

19. SOLDEVILA I BALART, Llorenç, op. cit., 1993, p. 32.

20. GARCÍ-SOLER, Jordi, Crónica apasionada de la Nova Cançó, Barcelona, Flor del Viento Ediciones, 1996, p. 39.

21. CARANDeli, Luis, «La crisis de la nova cançó», Triunfo, n. 369 (1969), Madrid, pp. 15-21. 
hecho que marca el cambio es el llamado "caso Serrat» entorno a su participación en el Festival de Eurovisión en 1968. Serrat, tras su grandísimo éxito a nivel nacional con sus primeros discos, es seleccionado por Televisión Española para representar a España en el Festival de Eurovisión de 1968 a celebrar en Londres. La revista Fonorama, como otras muchas publicaciones del momento, se congratula en sus páginas por la elección del joven cantante catalán e incluye en ellas una pequeña entrevista con él en la que afirma «sentirse nervioso por la responsabilidad" y que necesita recluirse "para pensar y concentrarme en el asunto» 22 . Precisamente en mitad de esa reclusión salta la gran bomba. El 25 de marzo de 1968 Serrat envía una carta a Televisión Española en la que manifiesta su negativa a participar en Eurovisión si no se le permite cantar en catalán el tema La, la, la, que ya había sido escogido como el candidato español. Por supuesto, la televisión estatal no admite tal órdago y no duda en sustituirlo por Massiel. El revuelo es enorme. La misma revista Fonorama, una de las publicaciones que más apoyo había ofrecido a Serrat, publica un amargo editorial titulado «El caso Serrat», en el que reflexionaba acerca del ambiente que rodea a la canción catalana y las posibles presiones que pudieran haber afectado a la decisión de Joan Manuel. La revista afirmaba: "No comprendemos muy bien porqué un cantante en catalán, sólo por el hecho de cantar algunas canciones en castellano, sin dejar de cantar en su lengua natal, vaya a ser un traidor a su tierra chica». Pero en el fondo la cuestión estaba clara: "A Joan Manuel Serrat se le planteó un dilema. Si era fiel a TVE y al público del resto de España, traicionaba al público de su tierra y a sí mismo. Si era fiel a sí mismo, y a su terruño, traicionaba a TVE y al resto del público. Tenía, por fuerza, que quedar mal con alguien. Joan Manuel Serrat ha dado más valor a lo que le rodea y a su sentir íntimo, que a la gloria nacional y europea ${ }^{23}$.

Muchos no quisieron ver en esto una cuestión política pero, desde luego, se convertía en tal en el momento en que Televisión Española vetaba a Serrat que, como ha contado Jordi García-Soler, no volvería a aparecer en pantalla hasta marzo de $1974^{24}$. Un hecho que no cambiaba los pareceres personales dentro de la Nova Cançó, pero que sí iniciaba un período del movimiento en el que las canciones, que antes eran pasadas por censura con cierta normalidad, van a comenzar a ser miradas con lupa por el censor, prohibiendo a partir de entonces, ya no tanto la grabación, sino la proyección radiofónica de algunos de los nuevos temas catalanes. Barbat, Pi de la Serra y Lluís Llach serían los más perseguidos por el fantasma de la censura. $Y$ no es que las nuevas canciones fueran de mayor dureza que antes, sino que la dimensión tomada por el movimiento y la lectura política que ciertos medios dieron al "caso Serrat", hicieron al Régimen seguir más de cerca este fenómeno de canciones catalanas.

22. MORer ALCÁNTARA, Fernando, "Eurovisión 68. Serrat representará a España", Fonorama, n. ${ }^{\circ} 43$ (1968), Madrid, pp. 25-26.

23. Artículo editorial «El caso Serrat", Fonorama, n. ${ }^{\circ} 45$ (1968), Madrid, p. 24.

24. GarCía-SOler, Jordi:, op. cit., 1996, pp. 42-43. 
La política de censura en ese momento va a consistir en reducir la difusión pública de estos cantantes, aprovechándose del mecanismo censor en vigor en esos momentos. Todas las letras de las canciones, antes de ser grabadas, pasaban por censura donde recibían dos calificaciones: la primera establecía si la grabación del tema se autorizaba o se denegaba. Y la segunda establecía si el tema, una vez grabado, era radiable o no. Esta segunda premisa va a ser muy recurrente con los cantantes de la Nova Cançó tras el "caso Serrat». Si la censura se cebaba con estos cantantes prohibiendo sus letras, pronto el público notaría un fuerte frenazo en su producción. Así que se va a optar por autorizar sus grabaciones pero calificar a los «singles» como "no radiables», con lo que limitaban la proyección pública de estos trabajos al frenar la publicidad que a un tema le daba el sonar en todas las emisoras de radio musical. Prácticamente todos los cantantes del movimiento van a sufrir esas medidas en este momento. Podemos citar temas variados como «L'amant del vent» de Delfí Abella ${ }^{25}$, "Assaig de càntic en el temps» de Guillermina Motta ${ }^{26}$ " "Cantarem la vida" de Raimon ${ }^{27}$, "Els que venen" de Enric Barbat ${ }^{28}$, "Poco antes de que den las diez" de Joan Manuel Serrat ${ }^{29}$, «Historia de una cuina» de Pau Riba ${ }^{30}$, "Paisatge» de Jaume Sisa ${ }^{31}$ o "La resurrecció dels morts» de Lluís Llach ${ }^{32}$, sólo por nombrar algunos ejemplos al azar.

Por supuesto, todo ello no puede dejar de entenderse fuera del marco de cambio social que suponen los años sesenta y la evolución que el Régimen va a experimentar hacia su final en los años setenta, al paso del deterioro físico del dictador. Los setenta comienzan como una década de contradicciones en la que, junto a la existencia de una mayor dureza y claridad de análisis que comienzan a realizar ciertas publicaciones culturales, se produce un recrudecimiento, en algunos casos, de la severidad censora. La cual no será ajena a la Nova Cançó a comienzos de los setenta. De hecho, desde las páginas de la revista Triunfo, y básicamente desde la firma de Vázquez Montalbán, comienzan a proliferar una serie de artículos denunciando el obligado silencio al que se ven sometidos algunos miembros del movimiento. En concreto, se habla de Enric Barbat como "un cantante maldito" ${ }^{33}$ y se denuncia la persecución y veto a otros como Pau

25. Instancia n. ${ }^{\circ} 138,10$ de octubre 1967. A.G.A., Sección Cultura, caja 45850.

26. Instancia n. $.^{\circ} 85,3$ de marzo 1967. A.G.A., Sección Cultura, caja 45858.

27. Instancia n. ${ }^{\circ} 654,8$ de noviembre 1968. A.G.A., Sección Cultura, caja 49994.

28. Instancia n. ${ }^{\circ} 315,4$ de junio 1968. A.G.A., Sección Cultura, caja 49994.

29. Instancia n. 126,9 de abril 1968. A.G.A., Sección Cultura, caja 49998.

30. Instancia n. ${ }^{\circ} 805,5$ de noviembre 1969. A.G.A., Sección Cultura, caja 50003.

31. Instancia n. ${ }^{\circ} 395,17$ de junio 1969. A.G.A., Sección Cultura, caja 50018.

32. Instancia n. ${ }^{\circ} 115,21$ de junio 1971. A.G.A., Sección Cultura, caja 50032.

33. VÁZOUEZ MontalbáN, Manuel, «Enric Barbat. Un cantante maldito», Triunfo, n. ${ }^{\circ} 412$ (1970), Madrid, pp. 25-26. Examinando los expedientes de censura se comprueba esta persecución. Un. ejemplo son las enormes dificultades para la grabación de un disco en 1968, donde el single y tema estrella "Amic Enric" es prohibido tajantemente por la censura. Ver Instancia n. ${ }^{\circ} 213,3$ de junio 1968. A.G.A., Sección Cultura, caja 49994. 
Riba a quien se le prohíbe cantar en el Palau de la Música de Barcelona ${ }^{34}$. Pero, sin duda, el icono que utiliza Montalbán como reflejo de la relevancia política y la persecución de la Nova Cançó es Raimon. De él dice que "se ha convertido en uno de los mitos del prohibicionismo nacional. La prueba de ello es el carácter de manifestación política que se ha dado a las últimas actuaciones universitarias del cantante ${ }^{35}$. La realidad en estos momentos, ya entrando en los setenta, era que se empezaba a abandonar la fórmula de declarar a las canciones «No radiables", para censurar completamente algunos temas sin escrúpulos. Probablemente esto venía dado por los cambios al frente del Ministerio (Fraga lo abandona en 1969) y de la sección de censura musical.

Indagando en los expedientes de censura del momento, quizás el ejemplo más significativo sobre Raimon y la censura lo encontramos en 1971. El 23 de noviembre de ese año se abre el expediente para la grabación de un nuevo disco de Raimon con diez canciones, que contiene temas suyos como «Sobre la por», "Contra la por», "Sobre la pau» o el ya conocido «Diguem no» y dos más pertenecientes a poemas de Ausiàs March. Al comprobar la traducción de las letras, el informe del censor dice lo siguiente: "Todas las canciones en su conjunto tienen una clara intención subversiva. Pueden autorizarse sin inconveniente la 6 y la 9 ("Elogi dels diners" y "Societat de consum»). La 7 y la 8 , si bien son clásicos de Ausiàs March, no dudo que se pretende darles una interpretación nada sana, por lo que las señalo como dudosas. El resto de las canciones, tanto en castellano como en catalán, resultan totalmente rechazables». En resumen, de un disco de diez canciones, finalmente sólo se admiten dos, por lo que la grabación del mismo resulta imposible y queda suspendida.

Aunque parezca lo contrario, esta postura "política» de algunos integrantes de la Nova Cançó, no es nueva, lo que pasa es que ahora se comienza a hablar claramente de ello. De hecho, en una entrevista a la revista Fans concedida en 1966, Raimon era muy tajante en su visión de la realidad que le rodeaba: «Sólo digo "no" a cuatro cosas: hambre, miedo, sangre y prisión. No estoy de acuerdo con el mundo en que vivimos... $>^{36}$. Lo que sucede a partir de los setenta es que se va a hablar más claramente del tema. La cuestión política empieza a envolver a la Nova Cançó y algunos de sus miembros, crispados con la situación que viven, empiezan a quejarse con mayor claridad al ser preguntados. Por ejemplo, Lluís Llach, que se convierte en uno de los miembros más perseguidos del movimiento, se expresa sobre el tema en las páginas de la revista Disco Exprés: «No sé cuando voy a tener canciones para el próximo disco. Ya se sabe que me cuesta

34. No sólo eso, sino que la mayoría de sus temas son prohibidos por la censura como "La castrança", "Vade retro corpus tentations» o "Maria Verge». Ver instancias n. ${ }^{\circ} 30\langle 9 / 1 / 1969), n .{ }^{\circ} 771$ (28/10/1969), n. ${ }^{\circ} 122(12 / 2 / 69)$, respectivamente. A.G.A., Sección Cultura, caja 50003.

35. Vázouez MonTalbán, Manuel, "El silencio de Raimon", Triunfo, n. 408 (1970), Madrid, pp. 30-32.

36. CRESPO, Ramón, "Raimon habla claro", Fans, n. 54 (1966), Madrid, pp. 8-9. 
mucho componer, principalmente porque todo lo que hago me lo "cepillan". Cada uno tiene su forma de expresarse, pero por lo visto la mía es fatal» ${ }^{37}$.

Pero no sólo se trata de una cuestión de prensa, sino que en muchos caso las canciones de la Nova Cançó, van a derivar en símbolos de una actitud contestataria ante el Régimen. Canciones nuevas como "L'Estaca», de Llach, se acabarán convirtiendo en auténticos himnos antifranquistas, mientras que otros temas más antiguos como "Al vent" $\mathrm{y}$ "Diguem No" de Raimon, "Que volen aquesta gent» de Maria del Mar Bonet o «la Gallineta» del propio Llach, son recuperadas por la juventud catalana y española en el mismo sentido. Incluso al margen de las canciones, va a ser crucial la postura de los propios cantautores que, si bien ya hacía años que viajaban al extranjero donde daban memorables recitales para exiliados, en ésta segunda etapa del movimiento van a tomar una actitud más comprometida actuando por toda la geografía española y, en especial, en las Universidades de Barcelona y Madrid, siendo de gran importancia social y política alguno de los recitales que Raimon ofreció en la Facultad de Ciencias de la capital española. Era el desarrollo definitivo de la canción protesta en España, que iba a estar apoyada por nuevas tendencias de la misma índole que, como comentaremos, empiezan a surgir en la geografía nacional.

Ya no se trataba sólo de reivindicar la cultura catalana, sino que ésta y el maltrato recibido por la dictadura, se convertía en símbolo de protesta contra la monocultura reinante en España desde 1939.

\section{IMPACTO SOCIAL Y SIGNIFICADO CULTURAL DE LA NOVA CANÇÓ}

Sin duda, el fenómeno de la Nova Cançó es uno de los más importantes de la cultura catalana contemporánea. Pero podría haberse quedado en un simple fenómeno regional y no haber trascendido como movimiento cultural para marcar también la historia española. Pero no fue así. Las causas de esto hay que buscarlas, sin duda, en las peculiaridades políticas de la España de Franco. Sin dictadura, no sólo hubiera sido improbable la existencia de tal movimiento, y éste no se hubiera extendido de esa forma por todo el país. La Nova Cançó era una respuesta cultural, en el momento oportuno de la dictadura, al discriminatorio trato que ésta dio a las culturas regionales que convivían en España. De ellas, la catalana fue la que levantó la bandera reivindicativa de una cultura de gran riqueza histórica. Al principio la reacción social, mientras que en Cataluña fue mayoritariamente de adhesión y compromiso, en el resto de España fue de mera observación y cierto desconocimiento.

Como hemos contado, fue en 1963 cuando la Nova Cançó, ya con algunos años de vida, irrumpía en las publicaciones españolas tras la victoria de Raimon y Salomé en el V Festival Internacional de la Canción Mediterránea. Pero esto no pasaba de ser simplemente una noticia anecdótica para los pocos que se fijaron en ella. Al paso del tiempo, poco se conocía fuera de Cataluña acerca

37. SierRA I FABRA, Jordi, "La vuelta de un prohibido Lluís Llach", Disco Exprés, n. ${ }^{\circ} 185$ (1972), Pamplona, p. 6. 
del movimiento, pero sí iban llegando algunos intérpretes, de los que España empezaba a fijarse en Raimon. En 1964, Julio Acerete, desde las páginas de la revista Índice, advierte a los lectores acerca de Raimon, un gran poeta catalán de una fuerza interpretativa muy destacable, y le augura un gran éxito en todo el territorio español ${ }^{38}$. Y no estaba equivocado. " $\mathrm{Al}$ vent" comienza a sonar por todo el país y se convierte en un tema conocido del gran público, con lo que éste comienza a interesarse por la figura del joven valenciano de Játiva. Otras publicaciones culturales empiezan también a fijarse en Raimon ${ }^{39} \mathrm{y}$, por fin, las revistas musicales se preguntan, como hacía Fonorama, "¿Qué es la nova cançó? ${ }^{40}$.

En 1965 las mismas revistas comienzan a llenar sus secciones de opinión de los lectores de reclamaciones, desde todos los puntos de España, de una mayor cobertura informativa sobre la Nova Cançó ${ }^{41}$. Las revistas empiezan a complacer a sus seguidores y la cobertura informativa a nivel nacional adquiere un nivel considerable.

Es el momento de la irrupción de Serrat y, con él, no sólo se disparan las ventas de la canción en catalán, sino que la Nova Cançó adquiere un nivel de popularidad grandísimo uniendo a la figura de Raimon la del nuevo ídolo catalán.

Ésta es la sucesión cronológica de cómo el fenómeno traspasa las fronteras de Cataluña pero, ¿dónde reside realmente el impacto social y cultural de la Nova Cançó?

En primer lugar, lo primero que debemos destacar del fenómeno es la grandísima importancia que, en ese momento histórico, tuvo el hecho de acercar la cultura catalana representada por canciones en catalán y sobre la vida catalana, al resto de un país que trataba de despertar del letargo cultural de un represivo primer franquismo. El calado que tuvo esa forma cultural regional sobre una sociedad "castellanizada" resulta, además de sorprendente, prácticamente suficiente para justificar la importancia del fenómeno. Pero ésta va más allá.

La Nova Cançó, no sólo fue algo que gustó a un gran número de españoles del momento, sino que también significó un ejemplo de reivindicación cultural que se siguió en otros lugares. Prácticamente el modelo catalán fue seguido en regiones como el País Vasco o Galicia, donde a fines de los sesenta se empieza a hablar de Nueva Canción Vasca y Gallega respectivamente ${ }^{42}$. Desde luego que

38. ACERETE, Julio C., «Raimon: un poeta que canta en catalán», Índice, n. ${ }^{\circ} 183$ (1964), Madrid, pp. 16-18.

39. En la revista Reseña aparece un interesante trabajo sobre Raimon y sus canciones. Ver PUIGJANER, José María, "Raimon, poeta de la canción catalana”, Reseña, n. ${ }^{\circ} 8$ (1965), Madrid, pp. 233-237.

40. Morer AlCántara, Fernando, "Qué es la Nova Cançó Catalana?", Fonorama, n. 14 (1965), pp. 10-11.

41. Como ejemplo, la revista Fans, en sus números del 42 al 50, publica una decena de cartas reclamando mayor atención a la Nova Cançó.

42. Estos fenómenos van a coger bastante fuerza a finales de los sesenta. El ejemplo es que la censura va a empezar a fijarse en hechos como las letras gallegas de Celso Emilio Ferreiro en Galicia o los temas en euskera de Mikel Laboa, por citar algunos ejemplos. Ver A.G.A., Sección Cultura, caja 49994. 
no tuvieron la repercusión cultural del movimiento catalán, pero simbolizaron también el despertar de las culturas regionales en España. Pero, por supuesto, la Nova Cançó tuvo su reflejo en la aparición en otros puntos de la península de una serie de cantautores comprometidos con la causa cultural y, más tarde, política, formando parte de la llamada "canción protesta». Figuras como Víctor Manuel en Asturias, Patxi Andión en el País Vasco, o Pablo Guerrero en Extremadura, continuaron en castellano un género y una forma de hacer que inequívocamente había partido de Cataluña. Todos ellos, jugaron un papel cultural de gran trascendencia como voz social en el final de la dictadura e incluso durante el proceso de transición democrática.

Eso si solamente hablamos de la geografía española, pues la Nova Cançó, desde la aparición de Raimon en París en $1966^{43}$, alcanzó gran popularidad fuera del territorio español, tanto en Europa como en Sudamérica, debido, principalmente, a su sintonía con los exiliados españoles. Ellos, que prácticamente sólo contaban con los recitales de Paco lbáñez en París, recibieron a los cantautores de la Nova Cançó como representantes de un movimiento cultural con el que se sentían identificados. Probablemente esta relación de algunos miembros de la Nova Cançó, sobre todo, Raimon, Llach y Montllor, con los exiliados europeos, contribuyó en gran medida a la consideración política del movimiento.

Lo que es claro es que, en los últimos años de dictadura, la Nova Cançó y, en especial algunos temas e intérpretes, se van a convertir en símbolos del antifranquismo, coreados por todo el territorio nacional, a pesar de los riegos que ello contenía. Hechos como escuchar a cientos de estudiantes cantar «Diguem no» junto a Raimon en la Facultad de Ciencias de la Universidad de Madrid, puede dar idea de hasta donde llega la importancia política, social y cultural de la Nova Cançó.

\section{CONCLUSIÓN}

A lo largo de estas líneas hemos pretendido ofrecer algunas claves que expliquen en qué consiste el fenómeno cultural de la "Nova Cançó" y su importancia en el panorama español del segundo franquismo. No se ha pretendido realizar un análisis profundo del movimiento y sus repercusiones sino, más concretamente, tratar de acercar el lector al nacimiento, evolución y relevancia del mismo en un momento histórico de cambio social y cultural en el seno de la España de Franco. De esas premisas, se pueden extraer algunas conclusiones.

Para comenzar, la «Nova Cançó Catalana» es un fenómeno cultural que nace a fines de los cincuenta en el seno de la burguesía barcelonesa con el objetivo de reivindicar y fortalecer una cultura catalana resentida desde la conclusión de la Guerra Civil por la represión posbélica y la monocultura establecida por

43. La cultura catalana y española del momento se hizo pronto eco de los grandes triunfos de la Nova Cançó en el extranjero. Sirva de ejemplo el artículo que la revista Serra D'or dedicó a la primera actuación de Raimon en París. Ver BERTRÁir, Teresa P., "Paris descobreix Raimon. Raimon a la Sorbona", Serra D'or, n. ${ }^{\circ} 6$ (1966), Barcelona, pp. 29-31. 
el régimen franquista. Además, se trata de un fenómeno cuya fuerza no se entiende sin la dictadura y esa represión de la que hablamos, pues este clima es el que consigue una rápida adhesión y apoyo de un amplio sector social catalán al movimiento. Pero, y esto hay que resaltarlo, en ningún momento se plantean, los pioneros del movimiento, dotar a sus canciones de un contenido bélico o reivindicativo, sino que simplemente tratarán, bien de describir su vida cotidiana, o de recuperar musicalmente textos catalanes olvidados.

Los objetivos primeros del movimiento no son, pues, políticos, pero esa reivindicación cultural, en el momento en el que está concebida, tiene por fuerza un carácter político que atravesará las fronteras catalanas para convertirse en bandera de la reivindicación de las culturas regionales en la España franquista. Precisamente ese carácter político se alimentará con las diferentes posturas en el seno de la propia "cançó" entorno a la defensa de la lengua, y con hechos de gran magnitud informativa como la negativa de Serrat a cantar en castellano en Eurovisión. A partir de entonces, la trascendencia política de ciertos miembros del movimiento va a ser incuestionable y va a estar reflejada, no sólo en la participación activa de éstos en recitales para exiliados españoles o en conciertos reivindicativos en las universidades del país, sino en el recrudecimiento de la censura con las creaciones de gente como Raimon, Llach, Montllor o Pau Riba, entre otros. Probablemente, al analizar las letras, empezamos a encontrar, a medida que avanzan los años, un cierto sentido crítico con el mundo que los rodea, que va a impregnar la mayoría de las creaciones de estos autores.

Pero si esta postura política posee importancia para el Régimen, es porque la popularidad del movimiento va a ser de carácter nacional y su influencia se trasmitirá por todo el territorio español, traspasando las fronteras de lo puramente musical o cultural, donde la influencia de la Nova Cançó fue importantísima en la consolidación de una "canción protesta española", inédita hasta el momento si exceptuamos algunas coplas aisladas o ciertos cantes flamencos de escasa popularidad. Es evidente que el carácter nacional del fenómeno es lo que le hace tomar fuerza como movimiento social y político de trascendencia en el segundo franquismo. Pero también es cierto que, ya no el nacimiento, sino el crecimiento de la Nova Cançó como fenómeno de masas, no puede ser comprendido fuera del contexto de cambio cultural que vive la sociedad franquista a partir de los años sesenta. El movimiento, pues, no sólo va a contribuir como pieza importante a ese cambio cultural sino que, al tiempo, nace de esa misma situación de cambio. Es decir, la Nova Cançó es, a la vez, causa y consecuencia de un período crucial en la reciente historia española, pues en él comienza a definirse culturalmente una juventud y una sociedad que será la gran valedora del proceso de transición democrática que España vivirá a fines de los setenta. Un proceso en el que, nuevamente, la popularidad y el simbolismo de la Nova Cançó jugarán un papel destacado en la concienciación social y la lucha por la democracia.

El ejemplo más evidente de que la Nova Cançó debe su importancia al contexto en el que nace y que, fuera de él, prácticamente carece de sentido, es que su final llegará precisamente cuando la democracia está plenamente instaurada 
en España y las culturas regionales hayan ganado su batalla cultural, siendo reconocidas y apoyadas por la Constitución y los Estatutos de Autonomía. En ese momento la "cançó" pierde la fuerza que la había consagrado y el interés popular que la convirtió en uno de los fenómenos culturales más importante de los años sesenta en España. 